\author{
Marta Bogusławska- \\ Tafelska ${ }^{1}$ \\ Natalia Malenko \\ Alina-Andreea \\ Dragoescu Urlica
}

\section{A 'NEWPARADIGMATIC' PERSPECTIVE ON EDUCATING STUDENTS BEYOND NARCISSISTIC MODELS. TOWARDS PSYCHO-LINGUISTIC QUALITY IN INTERPERSONAL COMMUNICATION}

\begin{abstract}
This paper proposes an ecological model of learning and communicating, which has been coined 'newparadigmatic' and which is applied here with regards to the co-relational and participative nature of educational processes and communication in general. Our point of view builds upon a novel paradigm of language learning ecology set within an organic environment, where participants interact and cooperate, as opposed to entrenched behavioural patterns of narcissistic self-centredness which have become pervasive in modern societies. This approach focuses on some essential concepts such as psycho-linguistic quality and the creation of ecologically holistic environments for learning how to communicate. The solution suggested by the authors keeps with the complexity of ecological models for language learning and aims at ensuring the high quality of language education in a meaningful newparadigmatic perspective.
\end{abstract}

Keywords: Eco-linguistics, communication, language learning, 'newparadigmatic', quality

\section{Introduction}

Contemporary Western science has reached its paradigmatic limits, which has triggered a host of unintended consequences. On the one hand, the intensity and number of psychological, social, and health-related problems people experience has been increasing; on the other hand, intervention programs and methods provided by scholarly work often fail to meet the growing social and individual needs. In this context, the paper identifies one of the problematic sideeffects generated by this malfunctioning system: the psychological-socialcommunicational phenomenon of narcissism, as experienced by students. First we outline the mainstream scientific definition of narcissism. Then we turn to an alternative perspective suggesting possible strategies for overcoming it which we find available, first as a theoretical proposal and then as an applicative intervention program. The proposal could be put into effect once we shift the paradigm within which we work on the issue in the first place.

\section{Methodology}

The research and discussion rely on methodologies for language teaching and learning put forth by the ecolinguistic and communicative approaches, including cooperative language learning. These methodologies regard the class as an ecology whose balance should be optimally

\footnotetext{
${ }^{1}$ Corresponding author: Alina-Andreea Dragoescu Urlica Email: andreeadragoescu@yahoo.com
} 
maintained, while interaction between learners is regarded as psycho-linguistic qualitative coherence in interpersonal relations ( $c f$. Dragoescu Urlica, 2018).

\section{Discussion - Proposal to start the scientific process of changing the paradigmatic stance}

The diagram below illustrates the mainstream direction of the scientific process and our theoretical proposal of changing the paradigmatic starting point when undertaking the study of the narcissism phenomenon in relation to the psycholinguistic quality of interpersonal communication.

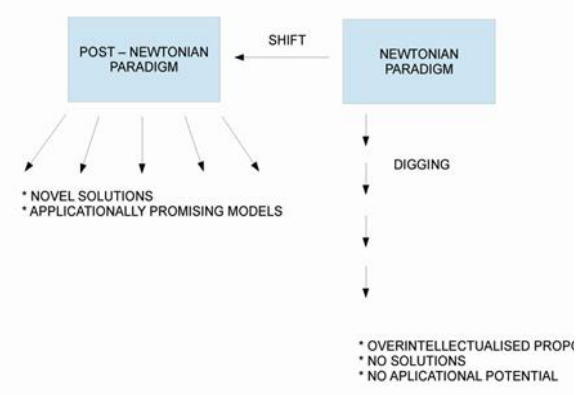

Figure 1. A paradigm shift and its benefits for the applied sciences (M.

Bogusławska-Tafelska, 2018).

Based upon our research hypothesis and considering our students' best interests, the major aim of our joint project is contributing to the qualitative development of communication in the 'newparadigmatic' culture of consciousness (Bogusławska, 2018).

The natural sciences, as well as social and language sciences, have focused on cognitivism and neurocognitivism (emergentism) as central meta-models. While it becomes increasingly evident in the scientific output across disciplines that scholars can see deeper and wider into life phenomena, at the same time the (neo)cognitivist meta-model is being used and abused in many cases to somehow find the theoretical background for what researchers are just beginning to perceive.

\subsection{Paradigms, thinking styles and collective status quo as the nonconscious steering mechanisms in modern science}

Objectivity in science remains a utopian concept. For example, the observer paradox no longer allows us to separate the observer from the observed, which questions the infallibility of cumulated observations and replications in the scientific method. It becomes a basic scientific prerequisite to start the scientific process with the conscious choice and specification of paradigmatic frames; thereafter, all considerations and research procedures are established within these frames and subsequently, scientific objectives are set for further research. The beginning of the new millennium gives us two alternatives in this respect: we can either choose the mainstream classical, materialistic-deterministic Newtonian paradigm or the postclassical, holistic paradigm.

When scholars choose the holistic paradigm as a point of departure in the scientific process, the research expands onto the multilevel grid of living systems and life processes, holistically intertwined and involved in dynamic relationships. The material forms have their nonmaterial motivations, their probabilistic unfolding and potential qualities. Entanglement is the main ontology of this postclassical framework and all values and qualities are sub-existing as potentials, being emergent intracategorically. Thus, grasping all this process on the whole, according to the postclassical paradigm, a linguist can work on two complementary levels: the surface level of forms and the deep level of underlying life processes, potentialities, values and relationships. 


\section{Intermationall Qualily Conference}

$\mathrm{RUAMUTY}$

Essentially, this deep level of analysis displays much more complexity than the modalities used in contemporary cognitive linguistics for specifying it. Therefore, we postulate this deep complexity level to be the site of creative potential intrinsic to human nature.

\subsection{Narcissism in the mainstream psychological research}

Narcissism, an increasingly pervasive phenomenon of modern societies, has been known to researchers and experts in the area of psychology and related fields for more than a century. There is some relevant discussion on narcissism in the areas of personal and social psychology, as well as clinical psychology and psychiatry (see Pincus \& Lukowitsky, 2010). Among particularly dehumanizing and anti-social traits, narcissism is characterized by lack of empathy, which is indispensable in successful communication with others from the point of view of ecological paradigms. Empathy is the ability to recognize someone else's feelings and identify with them. Heppert et al. (2014:3-4) suggest that, if empathy is analogically perceived as "social glue", subclinical/normal narcissists are "socially glueless." This is also characteristic of clinical/pathological narcissists, as corroborated by Krizan \& Herlache (2017:1), who state that "self-centeredness, vanity, and a lack of empathy" have been acknowledged as typical features in research on narcissism as a personality disorder. The authors note that even though narcissists seem attractive at the beginning of a social interaction, partners or colleagues tend to dislike them either after being in a relationship with them or after a longer period of acquaintance. As highly egocentric, narcissists are relatively bereft of empathy, which "underlies their antisocial behavior and interpersonal failures". Despite the fact that existing definitions of empathy vary or overlap to more or less significant degrees, the majority of researchers agree that "empathy is a core aspect of communion and concerns other-oriented cognitive and emotional responses" (Heppert et al., 2014:5).

\section{The ecolinguistic multimodal communication mechanism: beyond narcissism}

In view of the above theoretical background, we return to the postclassical, holistic perspective which we put forward in this study as our departure theoretical platform, in order to further approach the complex, psychological-communicative-social mechanism of narcissism. In order to develop our theoretical proposal for transcending narcissism via the educational intervention program, we propose the holistic ecolinguisitc model of human communication. We briefly characterise the model in what follows and we plan to extend it in future joint research.

The model proposed here follows the direction of communication as identified from a biosemiotics perspective: "communication is the interaction of lived bodies" (cf. Langewitz, 2009: 20). Accordingly, we acknowledge that "human communication is embodied and biologically situated' (Brier, 2016: 24). This should nonetheless not be understood in the sense in which cognitive grammarians, cognitive linguists and (radical) embodied cognitivists perceive and discuss embodiment ( $c f$. $\mathrm{M}$. Wellsby and P.M. Pexman, 2014; J. Kiverstein, 2012; Chemero, 2009). Our model involves the overall organism, in its micro-macro level organisation, from local, cellular layer of processes, to the (neuro)cognitive layer of processes, towards the nonlocal, transpersonal layers of processes. We propose to incorporate these basic layers into the analysis of how living systems communicate. In other words, human communication is not only (neuro)cognitive, navigated only on a 
QUA II II Y

DIFSIFAIDQI

neurocognitive

communication

linguistic forms

Neurocognitive language/communication constitute but one communication layer or modality. What we have been proposing in our ecolinguistic research (M. Bogusławska-Tafelska, 2013; 2015 ; 2016) it that apart from this common modality, humans have in potential a number of other communicative modalities, dispersed widely on other layers of organismic organisation which are active (nonconsciously, semi-consciously or consciously) in every communicator.

Hence, communication embraces a wide range of processes and relations, beyond the human central nervous system and beyond cognitive representations. The ecolinguistic model removes the focal point from the speaker-hearer exchange of material signals to the multidimensional grid perspective of living systems entering relationships ( $\mathrm{M}$. Bogusławska-Tafelska, 2016). These relationships are forming communicative, thoroughly creative links between living systems; their nature is:

- local/material - a traditional exchange of signals or signs;

- nonlocal/nonmaterial - where relationships are formed in the deep, noncausal, nonlocal level of life architecture.

\section{Conclusions The educational way forward}

To summarise the point we intended to make in this paper, narcissistic behaviours and life styles require the partnering recipient to make their impact. Narcissism, in its nonemphatic and highly manipulative expression, becomes operative in interpersonal and social settings, triggering unintended side-effects on communicative process.

Thus, it is the communicative awareness and the communicative skills of the other party involved in the given relation which needs to be addressed in the research and which constitutes the potential way out of the narcissistic - psychological, social and cognitive - impasse. We propose in our model that by modifying our awareness as conscious communicators, we can remove ourselves from potential narcissistic dyads, while remaining emphatically neutral with regard to narcissistic persons sharing our living space. So, this communicativepsychological disengagement does not imply conflict, negation or any form of negative labelling. An ecolinguistically competent communicator has learned how to identify and consciously confront the narcissistic profile he/she comes in contact with - which enables opting for a conscious communicative behaviour which helps moving beyond pathological patterns discussed above.

\section{References:}

Bogusławska-Tafelska. M. 2013. Towards an ecology of language, communication and the mind. Frankfurt am Main: Peter Lang.

Bogusławska-Tafelska, M. 2016. Ecolinguistics. Communication processes at the seam of life. Frankfurt am Main: Peter Lang.

Bogusławska-Tafelska, M. and M. Haładewicz-Grzelak (eds.). 2017. Communication as a life process. Beyond human cognition. Newcastle upon Tyne: Cambridge Scholars Publishing.

Bogusławska-Tafelska, Marta. 2018. 'A Culture of Consciousness' - Towards Functional Educational Models to Implement It'. Forthcoming.

Brier, S. 2016. 'Cybersemiotics as a transdisciplinary model for interdisciplinary biosemiotics pharmacology and medicine'. In Goli, F. (ed). Biosemiotics medicine. Healing in the world of 
meaning. Switzerland: Springer.

Chemero, A. 2009. Radical embodied cognitive science. London/New York: MIT Press.

Cibangu, S. K. 2010. 'Paradigms, methodologies, and methods'. Library and Information Science Research, vol. 32. 177-178.

Davis, J. V. and J. M. Canty. 2015. 'Ecopsychology and transpersonal psychology'. In The Wiley Blackwell handbook of transpersonal psychology. Chichester: Wiley Blackwell. 597-611.

Dragoescu Urlica, Alina-Andreea. (2018). "The Ecology of Language as an Optimal Learning Model”. In Quaestus Multidisciplinary Research Journal, 13/2018 (VII), pp. 201-210.

Fleck, L. 2007a [1929]. 'O kryzysie 'rzeczywistości'. In Werner, S., Zittla, C. and F. Schmaltz (eds.). Style myślowe i fakty. Warszawa: Wydawnictwo IFiS PAN. 55-65.

Fleck, L. 2007b [1935]. 'O obserwacji naukowej i postrzeganiu w ogóle'. In Werner, S., Zittla, C. and F. Schmaltz (eds.). Style myślowe i fakty. Warszawa: Wydawnictwo IFiS PAN. 113- 147.

Fleck, L. 2007c. [1946]. 'Problemy naukoznawstwa'. In Werner, S., Zittla, C. and F. Schmaltz (eds.). Style myślowe i fakty. Warszawa: Wydawnictwo IFiS PAN. 148-162.

Friedman, H. L. and G. Hartelius (eds.). The Wiley Blackwell Handbook of transpersonal psychology. Chichester: Wiley Blackwell.

Goli, F. 2016. Biosemiotic medicine. Healing in the world of meaning. Dordrecht: Springer.

Gosciniak J. and M. Mocek. 2008. 'Narcyzm i patologia narcystyczna w ujęciu Psychologii Self Heinza Kohuta'. Roczniki Psychologiczne. Vol. XI. 2. 7-26.

Kiverstein, J. 2012. 'The meaning of embodiment'. In Topics in Cognitive Science. 4(4):740-58.

Langewitz, W. 2009.' A theory of psychosomatic medicine: an attempt at an explanatory summary'. In Semiotica. 173-1/4. 431-452.

Lasch C. 1976. The Culture of Narcissism. W.W. Norton \& Company Ltd.

Luchner A., F. \& S. Tantleff-Dunn. 2016. 'Dysfunctional Empathy in Vulnerable Narcissism'. North American Journal of Psychology.18(3):597-610.

Penrose, R. 2005. Shadows of the mind. London: Vintage.

Pinkus A. L. \& Lukowitsky, M.R.. 2010. 'Pathological Narcissism and Narcissistic Personality Disorder'. Annu. Rev. Clin. Psychol. 2010. 6:8.1-8.26.

Plotnitsky, A. 2004. 'The unthinkable: nonclassical theory, the unconscious mind and the quantum brain'. In Globus, G. G., Pribram, K. H. and G. Vitiello (eds.). Brain and being. At the boundary between science, philosophy, language and arts. Amsterdam/Philadelphia: John Benjamin's. 29-45.

Rohmann E., Neumann E., Herner M. J., \& H.W. Bierhoff. 2012. 'Grandiose and Vulnerable Narcissism Self-Construal, Attachment, and Love in Romantic Relationships'. European Psychologist. 2012; Vol. 17(4):279-290.

Vitiello, G. 2001. My double mind. Amsterdam/Philadelphia: John Benjamins.

von Bertalanffy, L. 1968. General systems theory. New York: George Braziller.

Walach, H., and N. von Stillfried. 2011. 'Generalised Quantum Theory - Basic Idea and General Intuition: a Background Story and Overview'. Axiomathes. vol. 21:185-209.

Walach, H. 2013. 'Generalised Quantum Theory - A new approach for communication?'. Plenary lecture at Olsztyn Linguistic Conference. Olsztyn: University of Warmia and Mazury.

Walach, H., von Lucadou, W. and H. Römer. 2014. 'Parapsychological phenomena as examples of Generalized Nonlocal Correlations-a theoretical framework'. Journal of Scientific Exploration. Vol.28. No 4. 605-631.

Wellsby, M. and P.M. Pexman. 2014. 'Developing embodied cognition: insights from children's concepts and language processing'. In Frontiers in Psychology. Vol. 5 (506). 
Marta Bogusławska-

Tafelska

Researcher in the process of changing affiliation martabt@ibnet.pl

\section{Natalia Malenko}

Lomza State University of

Applied Sciences,

Poland_nmalenko@pwsip.edu.pl

\section{Alina-Andreea Dragoescu}

Urlica

USAMVB 'Regele Mihai I al

Romaniei',

Timisoara, Romania

andreeadragoescu@yahoo.com 